\title{
Experimental Study of Torque Using a Small Scoop on the Lunar Surface
}

\author{
Long Xue, ${ }^{1,2}$ Baichao Chen, ${ }^{3}$ Zhenjia Zhao, ${ }^{1}$ Zhaolong Dang, ${ }^{3}$ and Meng Zou ${ }^{1}$ \\ ${ }^{1}$ Key Laboratory for Bionics Engineering of Education Ministry, Jilin University, Changchun 130022, China \\ ${ }^{2}$ School of Mechatronic Engineering, East China Jiaotong University, Nanchang 330045, China \\ ${ }^{3}$ Institute of Spacecraft System Engineering, China Academy of Space Technology, Beijing 100083, China \\ Correspondence should be addressed to Meng Zou; zoumeng@jlu.edu.cn
}

Received 22 May 2016; Accepted 7 September 2016

Academic Editor: Christopher J. Damaren

Copyright (c) 2016 Long Xue et al. This is an open access article distributed under the Creative Commons Attribution License, which permits unrestricted use, distribution, and reproduction in any medium, provided the original work is properly cited.

\begin{abstract}
Chinese missions to the moon are planned to sample the regolith and return it to the earth. Microscale excavators may be good candidates for these missions, as they would significantly reduce the launch mass. Thus, it is necessary to research the interaction between the scoop and the regolith being sampled. We present the development of a simple apparatus to measure excavation torque. All tests were conducted using TYII-2 regolith simulant with gravels. The test results show that, under loose regolith conditions, the penetrating angle and the bulk density had a great influence on the excavation torque, while the rotating speed had little effect. However, when the bulk density was compact, the rotating speed did influence the excavation torque. The excavation torque increased sharply when the scoop encountered the gravels; actually, some of the parameters will influence the value of the torque such as the diameter, quantity, and position and inbuilt depth of the gravels. When the excavation torque sharply increases, the operation should be immediately stopped and checked.
\end{abstract}

\section{Introduction}

Excavation sampling is an effective technique to obtain superficial regolith and gravels; thus it has been used in lunar and Martian explorations widely. The Lunar Exploration Program of China plans to sample the lunar surface using a microscale excavator sampler and then return to earth [1]. Excavation requires a high level of interaction between the scoop of the sampler and the medium being sampled [2]. The forces and the torque of the interaction between the scoop and the regolith depend on the geometry, the regolith material characteristics, and the operating conditions.

As the excavation material is not always homogenous, there may be considerable variation in the soil properties which contribute to the soil-tool interaction force. Highly variable loads can cause damage to the structural components and elements of the power transmission when the loads exceed a certain level [3]. An accurate estimate of the soiltool interaction is critical in designing an efficient system and it can reduce the launch costs, minimize the operation costs, and also enhance reliability of the system [4].
In order to improve the adaptability of the superficial sampling apparatus and the excavation tool, many countries have started to develop test equipment and methods in studying the interaction between the tools and the regolith. A study by Bernold on the mechanics of lunar excavation showed that traditional excavation below $20 \mathrm{~cm}$ is extremely difficult due to the high density of the lunar soil, and the existence of gravels further complicates the operation [5]. Johnson and King measured the horizontal and vertical forces of excavation with a microscale bucket wheel and evaluated whether a sojourner size $(20 \mathrm{~kg})$ extraterrestrial excavation machine was practical [6].

King et al. [7] measured the force which is required to push a narrow $(2.5 \mathrm{~cm}$ wide $)$ square and round rods through a control material at different cut depths. They advised that the lunar missions should use a series of shallow cuts to reduce equipment size and power requirements. The NASA Glenn Research Center expanded on the work of Bucek et al. [8]; they presented results from multiple bearing and excavation tests conducted using a replica of the Surveyor SMSS. The surface profile of the soil deformation 
TABLE 1: Parameters of Lunar Regolith Simulant (TYII-2).

\begin{tabular}{lccccccc}
\hline & $\begin{array}{c}\text { Specific density } \\
\mathrm{g} / \mathrm{cm}^{3}\end{array}$ & Moisture content $\%$ & $\begin{array}{c}\text { Bulk density } \\
\mathrm{g} / \mathrm{cm}^{3}\end{array}$ & Porosity $\%$ & Cohesion $/ \mathrm{kPa}$ & Angle of internal friction $/^{\circ}$ & $d_{50} / \mu \mathrm{m}$ \\
\hline TYII-2 & 2.73 & 0.52 & $1.09-1.66$ & $38.2-60.1$ & 0.036 & 30.47 & 40.8 \\
Regolith & $2.90-3.33$ & 0.0 & $0.83-2.29$ & $42.0-54.0$ & $0-0.59$ & $30-50$ & $40-130$ \\
\hline
\end{tabular}

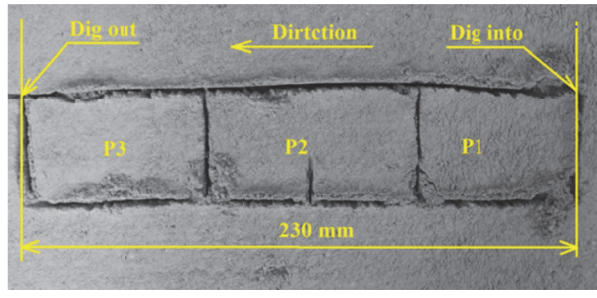

(a) Position

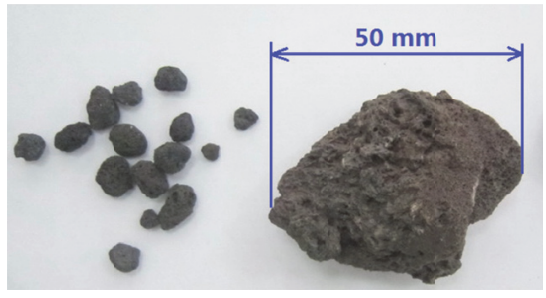

(b) Gravels

FIGURE 1: Lunar surface simulant.

surrounding the scoop during the bearing tests demonstrated the highly compressible nature of the loose soil beds [9]. Green and Zacny conducted percussive excavation tests at $101 \mathrm{kPa}$ and $600 \mathrm{~Pa}$ pressure in the JSC-1A soil simulant. The results suggested that a reduction in excavation forces at Mars pressure will translate to lower excavation energies on the planet directly [2].

Several experimental studies have investigated the effects of gravity on soil properties. Bui et al. [10] carried out soil cutting experiments in a low gravity environment to investigate excavation forces. Boles et al. [11] investigated the mechanism of soil excavation under partial gravity conditions by experimental model and numerical study using Toyoura sand and the Japanese lunar soil simulant.

A number of soil-tool interaction theories and methods have been developed to find the excavation force of a simple blade [12]. However, an excavation force mechanism like this is not yet well understood. Most researchers have studied Mars or lunar excavation experimentally, using materials including dry, compacted play sand, lunar simulant, and a mixture of sand and gravel. There are few studies on the influence of gravels and compact soil on excavation, although the scoop often encounters these problems in practical excavations.

The purpose of this research is to experimentally test a microsize scoop excavation system using different regolith parameters and operation conditions, to determine whether a change in these affects the torque during sample excavation. We describe the design of a simple excavation apparatus to simulate the interaction of a microsize scoop (approximately the size of the curiosity robot) with regolith and estimate the different regolith simulant parameters from the measured resistance torque. All of the tests were conducted in TYII-2 regolith simulant with specified gravels.

\section{Experimental Setup and Methods}

2.1. Lunar Surface Simulant. We used regolith simulant TYII$2[13]$ to test the excavation torque. The black-grey volcanic ash from Jinchuan city in Jilin province was selected as the raw material and transformed it into regolith simulant by controlling the particle size parameters. The particle size of TYII-2 is small and close to the lower limits of the lunar regolith, while its mechanical properties are close to the real regolith [13]. The elementary parameters of regolith and simulant $[14,15]$ are shown in Table 1.

Based on pictures from the Yutu lunar rover, we know that the lunar landing surface has gravels of different diameter. The size, shape, and position of the gravels are random, which could affect the excavation sampling. In fact, the gravels can cause the resistance of excavation to increase sharply, and the resistance of excavation could damage the equipment and even result in the failure of the sampling plan. Thus, it is necessary to test and analyze the change of the resistance with gravels and the regolith.

The position of gravels on the lunar surface is random. However, for maximum efficiency and validity, we placed the gravels at different positions based on the track of the scoop in the test. The excavation area was divided into three sections, P1, P2, and P3, from beginning to end (Figure 1(a)). The gravels were volcanic basalt from Jinchuan city, Jilin province, with diameters between 3 and $50 \mathrm{~mm}$ (Figure 1(b)).

A soil penetrometer was used to determine the regolith simulant condition before each excavation test. The gradient of the penetration force versus depth, in conjunction with the value of the projected cone area, was used to calculate the cone index, ensuring the consistency of the regolith simulant in different tests.

2.2. Excavation Measurement Apparatus. The test equipment is shown in Figure 2. It is designed to enable the adjustment of various excavation parameters; at the same time, the test equipment can acquire excavation data, such as excavation torque, angle, and time. The equipment comprises the following subsystems: a rigid soil bin, a frame, a power source to provide the digging power, and a sensing and data acquisition system to acquire and process data from the excavation. 


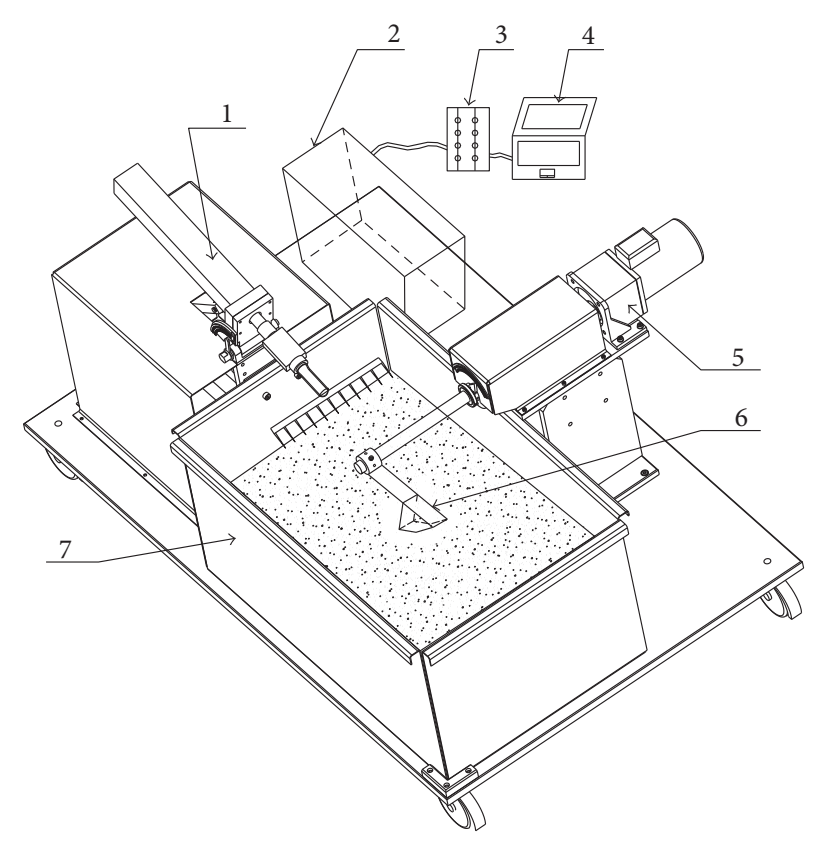

Figure 2: Excavation test equipment, (1) driving motor and preparation tool, (2) control box, (3) data acquisition unit, (4) computer and data acquisition software, (5) driving motor for the scoop, (6) scoop, and (7) soil bin, regolith simulant, and gravels.

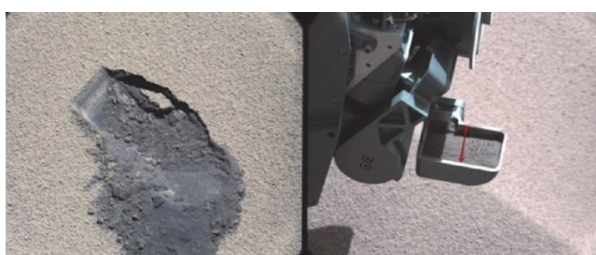

(a) Curiosity scoop excavating
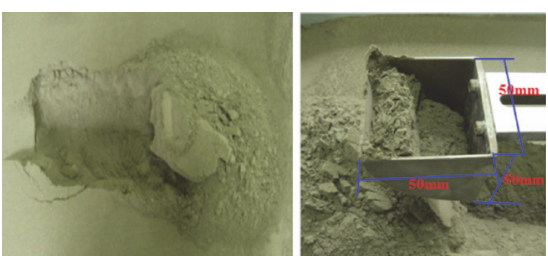

(b) Testing scoop excavating

FIgURE 3: Excavation comparison between the curiosity scoop and the testing scoop.

The torque sensor and encoder are mounted between the speed reducer and the scoop, to measure excavation torques. Data are acquired using a six-channel data acquisition board with 16-bit resolution. The signal inputs were connected in differential mode to the data acquisition device. Data acquisition software was prepared by Visual Basic, which was used to acquire the raw voltages from the internal strain segues on the torque sensor.

Based on experimental requirements, the excavation torque can vary from $0.5(\mathrm{~N} \cdot \mathrm{m})$ up to $50(\mathrm{~N} \cdot \mathrm{m})$ for a small excavation scoop. A power source, which provides up to a maximum of $90 \mathrm{~W}$, was deemed to be sufficient for low-speed soil excavation sampling. All of the regolith simulant was dried and placed in a rigid soil bin $800 \mathrm{~mm}$ long, $500 \mathrm{~mm}$ wide, and $400 \mathrm{~mm}$ deep, and the bin was then attached to the plate. The scoop referred to the style of curiosity (Figure 3(a)), with a length of $50 \mathrm{~mm}$, a width of $50 \mathrm{~mm}$, and a depth of $50 \mathrm{~mm}$ (Figure 3(b)).

2.3. Test Procedure. All the parameters such as the bulk density, gravel distribution, penetrating angle, and rotating speed are included in the test. The first step of the test was the preparation of the regolith simulant. The bulk density of the lunar regolith simulant is $1.09-1.66 \mathrm{~g} / \mathrm{cm}^{3}$, which can be divided to three states, loose, natural, and compact, and is determined by the cone index. The relationship between the cone index and the bulk density is shown in Figure 4 . We prepared the regolith simulant for every test to ensure a consistent cone index (Figure 4(b)).

The second step was to adjust the rotating speed, which was controlled by the driving motor. The third step was to adjust the penetrating angle by controlling the space between the shaft and regolith simulant surface (Figure 5).

\section{Data Analysis and Results}

3.1. Failure Mode of Regolith Simulant. Excavation sampling can be divided into three stages, namely, digging into, digging out, and uplift. In each of the three stages, the regolith was sheared and compacted by the scoop, leading to regolith failure. The soil condition, rotating speed, and penetrating angle had an effect on the failure planes. Figure 6 provides a comparison of the soil failure geometry between six different points in the timeline. From Figure 6 we can see that the 


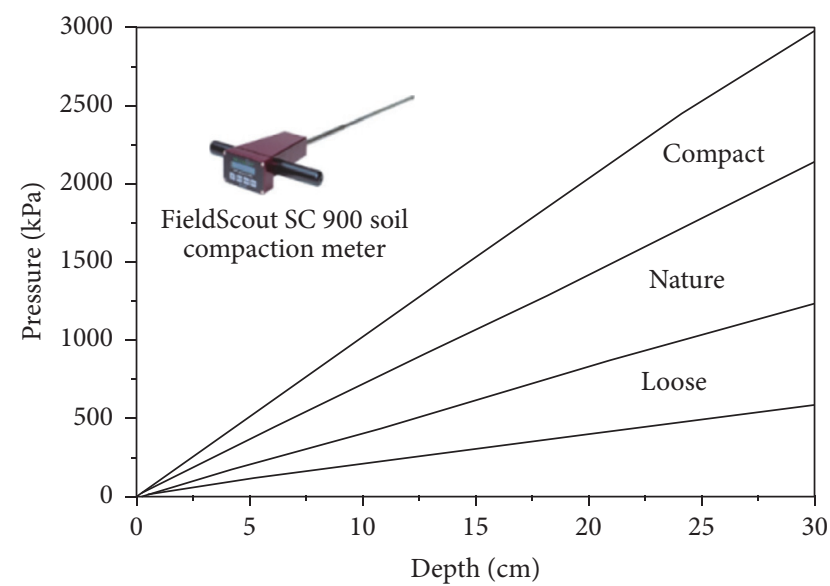

(a) Cone index

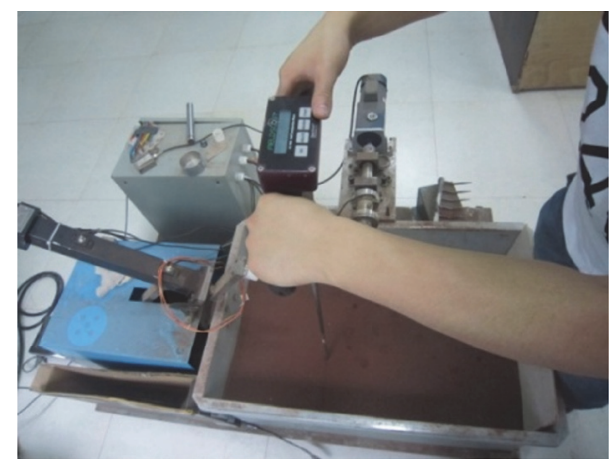

(b) Cone index testing

FIGURE 4: Preparation of the soil.

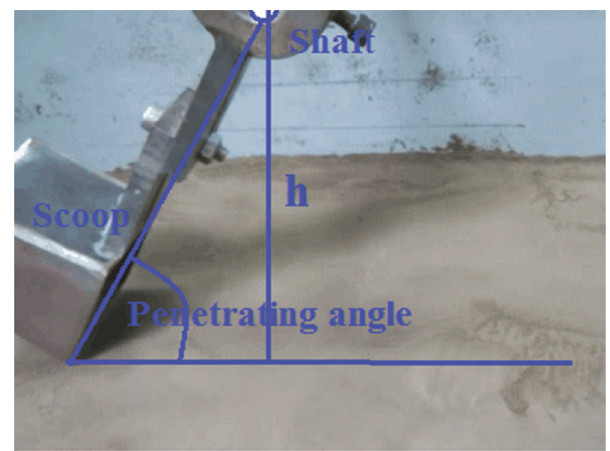

FIGURE 5: Penetrating angle control.

failure mode changed. Firstly, a soil arch was generated in front of the scoop; secondly, the soil cracked, the spaces increased over time, and finally the soil broke and was stacked.

The penetrating angle had a great influence on the failure of the regolith simulant. Figure 7 shows the failure model of the simulant after excavation by a scoop using a 3dimensional scanning on a different penetrating angle. From Figure 7, we can see that the volume of the regolith simulant in the scoop increased when the penetrating angle decreased.

When the penetrating angle was 30,45 , and 60 degrees, the width of the destructive area was $229.89 \mathrm{~mm}, 233.18 \mathrm{~mm}$, and $187.25 \mathrm{~mm}$, respectively, while the length was $501.14 \mathrm{~mm}$, $476.48 \mathrm{~mm}$, and $399.8 \mathrm{~mm}$, respectively, and the depth was $64.82 \mathrm{~mm}, 65.8 \mathrm{~mm}$, and $48.86 \mathrm{~mm}$, respectively.

The excavation torque versus angular displacement is shown in Figure 8. In the digging into stage, the excavation torque increased sharply, mainly due to an increase in the cutting intension of the soil and an increase in the friction force with the increasing area between the scoop and the regolith simulant. In the digging out stage, the excavation torque decreased because of the contact area, and the cutting line declined. In the uplift stage, the excavation torque increased slowly due to an increase in the component of gravity perpendicular to the scoop handle.

3.2. Excavation Torque. The influence of the rotating speed on the excavation torque is plotted in Figure 9, showing an obvious effect at the 30-degree penetrating angle, but not at the 45- and 60-degree angles, when the regolith was loose.

The penetrating angle had a strong influence on the excavation torque (Figure 9), which was found to increase with decreasing angle. The maximum excavation torques recorded for penetrating angles of 30, 45, and 60 degrees were $19.43 \mathrm{~N} \cdot \mathrm{m}, 8.06 \mathrm{~N} \cdot \mathrm{m}$, and $2.69 \mathrm{~N} \cdot \mathrm{m}$, respectively. The quality of the regolith in the scoop, the cutting force, and the friction between the scoop and the regolith led to the change in excavation torque. The penetrating angle determined the quality and the volume of the regolith simulant in the scoop, and the small penetrating angle had a long excavation failure plane, so the torque increased with the decreasing penetrating angle.

The rotating speed had a great influence on the excavation torque when the bulk density was compact (Figure 10). The maximum excavation torque at $0.56 \mathrm{r} / \mathrm{min}$ increased $67 \%$ compared to at $0.17 \mathrm{r} / \mathrm{min}$. On the whole, the excavation torque increased with increasing rotating speed, especially under compact regolith conditions.

The bulk density also influenced the excavation torque (Figure 11), along with the cone index, and enhanced the shear strength and the bear capacity, leading to the increase in cutting force and friction and, in turn, an increase in the excavation torque. The maximum excavation torque of the natural and compact regolith increased $217.7 \%$ and $363.2 \%$, respectively, compared to the loose regolith at the 45 -degree penetrating angle. The maximum excavation torque of the natural and compact regolith increased $43.5 \%$ and $409.7 \%$ compared to the loose regolith at the 60-degree penetrating angle. The bulk density of the lunar surface changed with depth which caused the torque to fluctuate wildly.

When the excavation explorer was sampling, the surrounding environment was complicated, with the shape, size, 


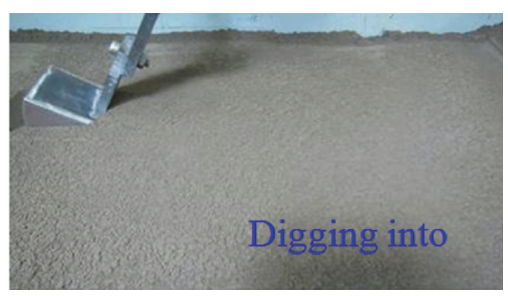

(a) $28 \mathrm{~s}$

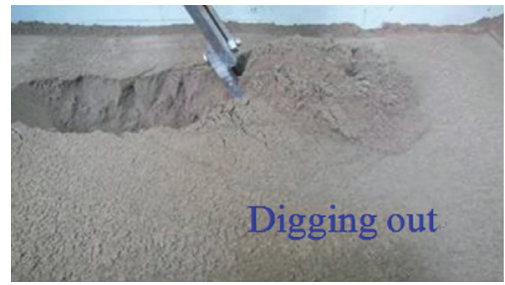

(d) $85 \mathrm{~s}$

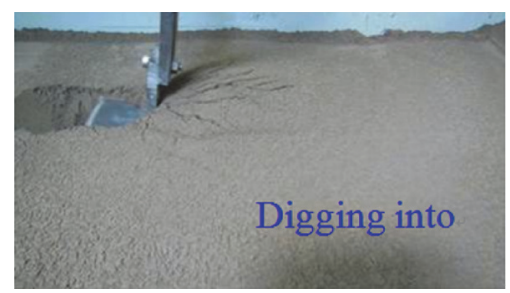

(b) $48 \mathrm{~s}$

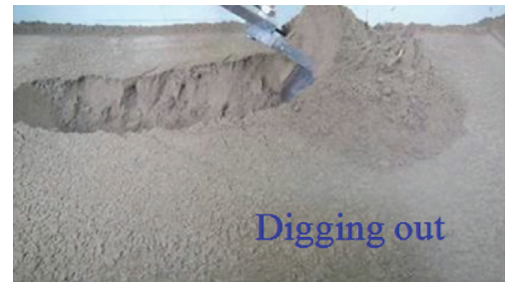

(e) $114 \mathrm{~s}$

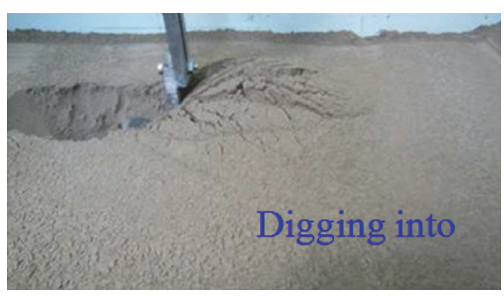

(c) $61 \mathrm{~s}$

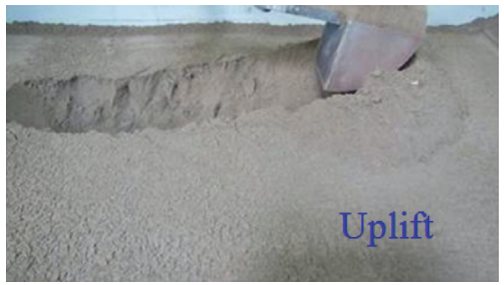

(f) $134 \mathrm{~s}$

FIGURE 6: Soil failure in the excavation test. The penetrating angle was 30 degrees, the soil condition was loose, and the rotation speed was $0.28 \mathrm{r} / \mathrm{min}$.
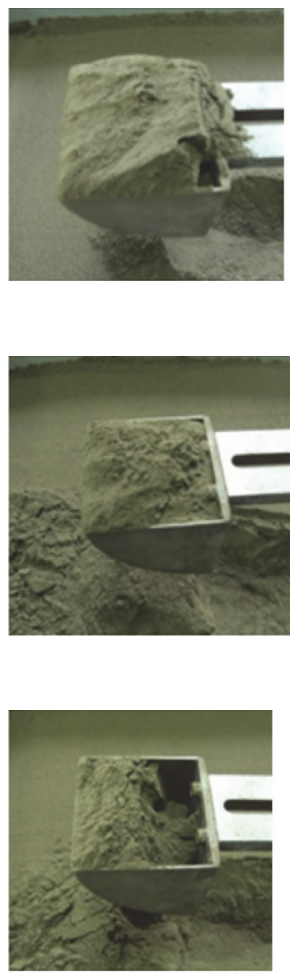
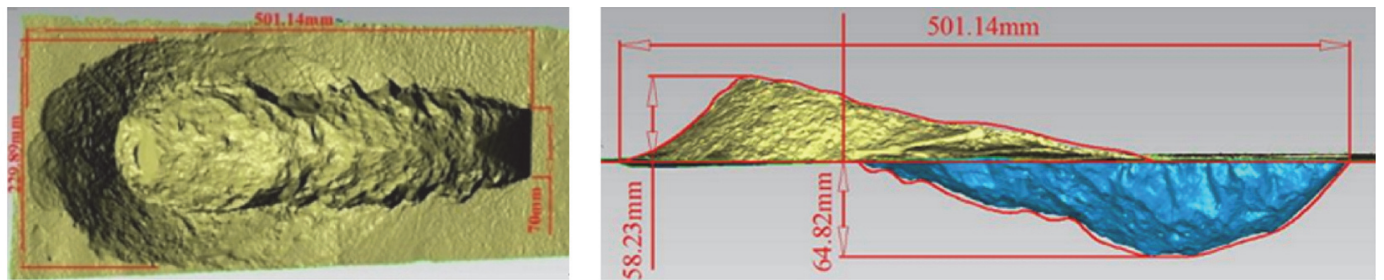

(a) Penetrating angle of $30^{\circ}$
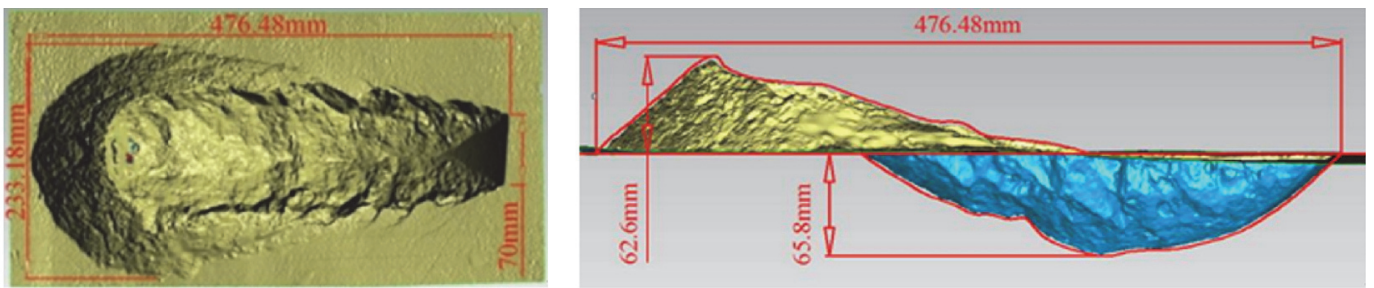

(b) Penetrating angle of $45^{\circ}$
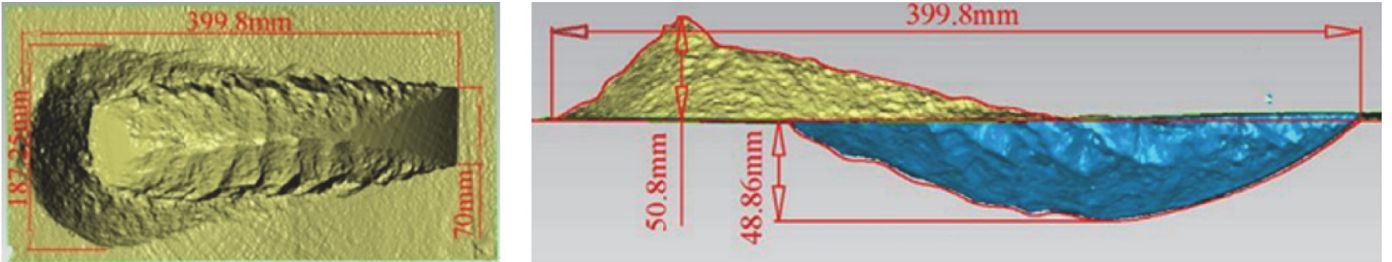

(c) Penetrating angle of $60^{\circ}$

FIGURE 7: Penetrating angle influence on the failure model. The soil condition was loose, no rocks were present, and the rotation speed was $0.28 \mathrm{r} / \mathrm{min}$.

position, and number of gravels influencing the interaction between the scoop and the regolith. It was difficult to rebuild a similar lunar surface environment. We tested the influence of the disposition of gravel on the excavation torque. The excavation area was divided into three parts (Figure 1), the length of the gravel was approximately $50 \mathrm{~mm}$, and one-third of the gravel was inbuilt underground. The angular displacement versus the excavation torque is shown in Figure 12. The excavation torque increased sharply when the scoop met and pressed against the gravel. The scoop excavated the gravel and the torque started to level out. The maximum torque was greater when the gravel was placed at the digging into stages 


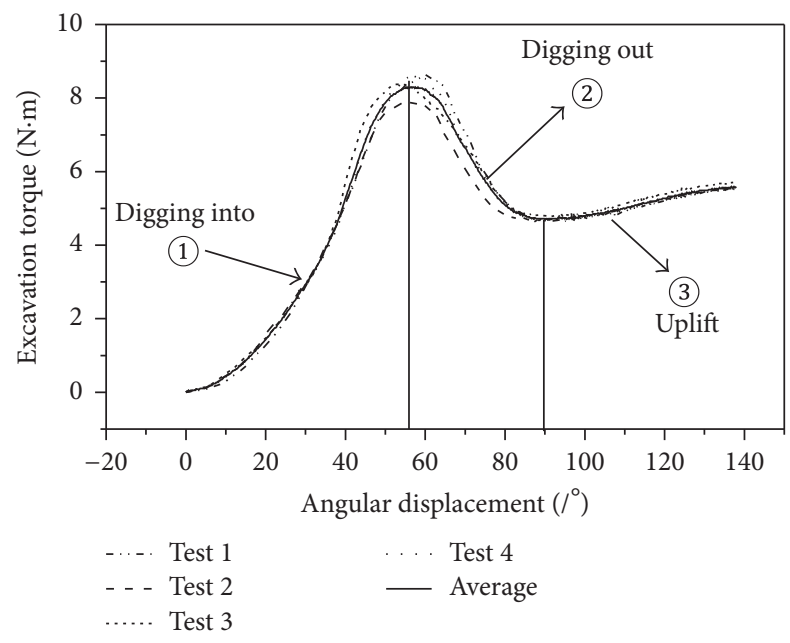

FIGURE 8: Torque versus angular displacement.

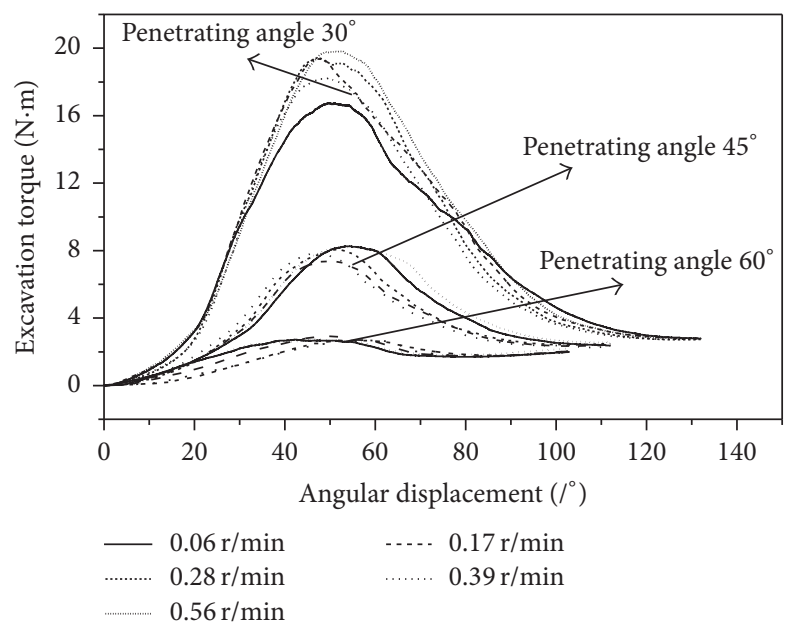

FIGURE 9: Rotating speed and penetrating angle influence on the excavation torque. The regolith condition was loose; the penetrating angles were 30,45 , and 60 degrees.

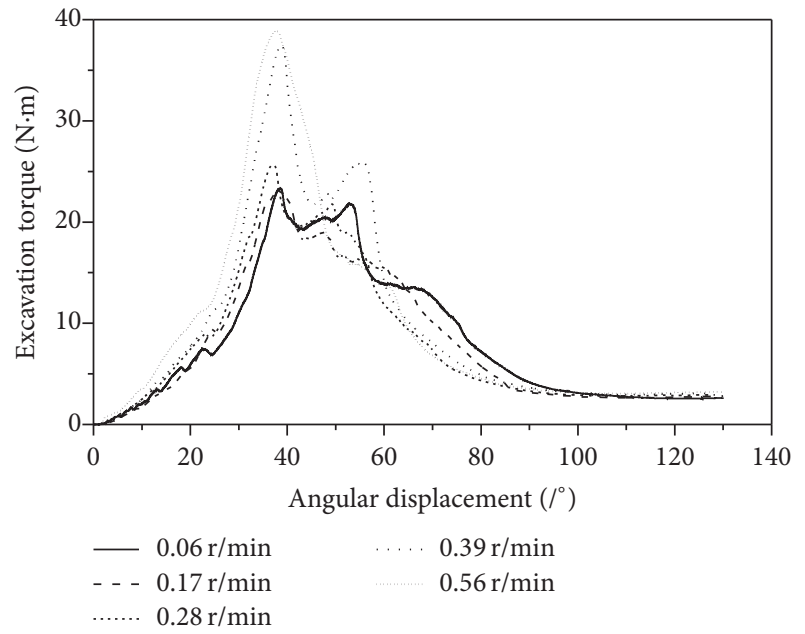

FIGURE 10: The influence of rotating speed on the excavation torque. The regolith condition was compact and the penetrating angle was 45 degrees.

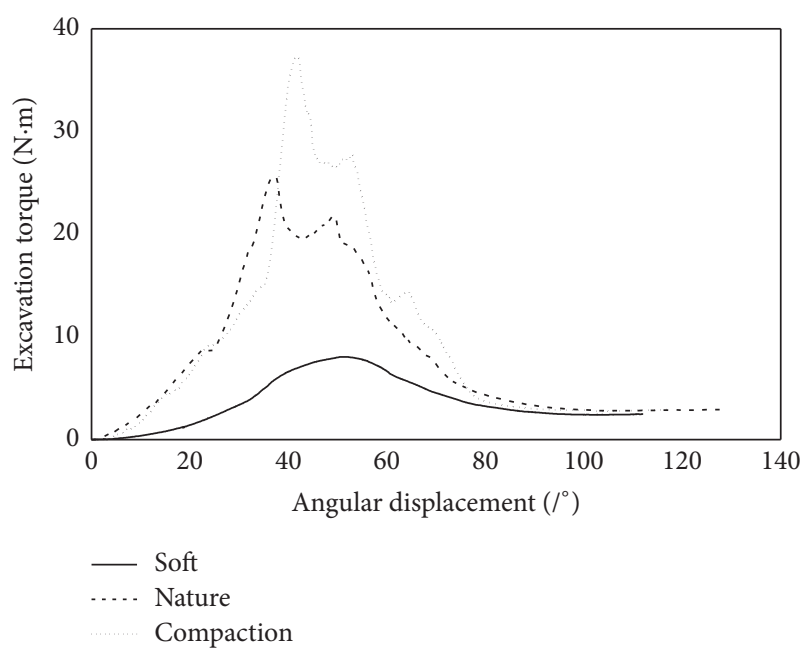

FIGURE 11: The influence of bulk density on the excavation torque. The bulk densities were soft, nature, and compaction, the rotating speed was $0.28 \mathrm{r} / \mathrm{min}$, and the penetrating angle was 45 degrees.

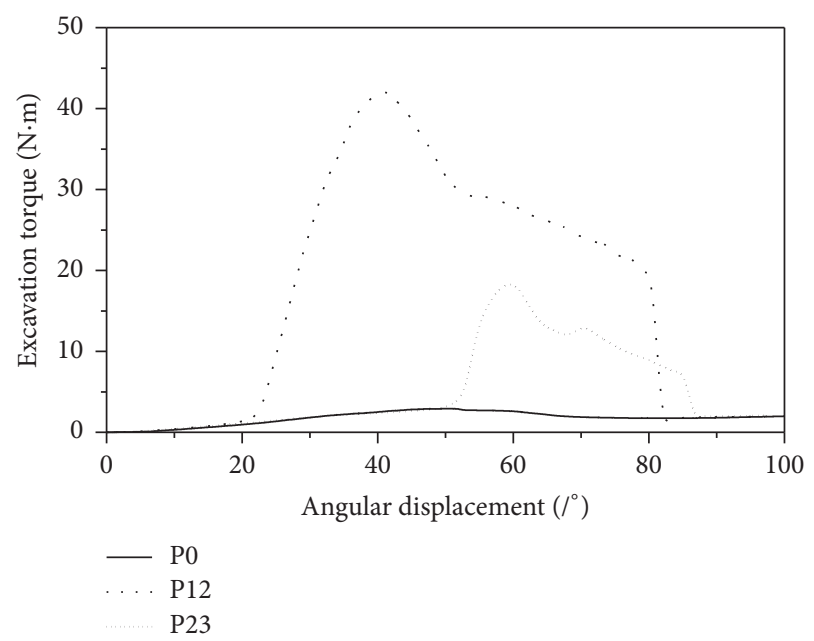

FIGURE 12: Influence of the gravel position on the excavation torque. The bulk density was loose, the penetration angle was 60 degrees, the rotating speed was $0.28 \mathrm{r} / \mathrm{min}$, P0 contained no gravels, P12 contained one large gravel in the P1 area, and P23 contained one large gravel in the P2 area.

(P1) than at the digging out stages (P2), and the maximum torque of P12 increased by $1463.6 \%$ over the $\mathrm{P} 0$ value, while that of P23 increased by $581.4 \%$ over P0.

Figure 12 indicates that the position of the gravel greatly influenced the excavation torque. A preliminary analysis suggested that when the gravel was placed in the P1 area (Figure 13), the scoop rotated and it would produce a downward motion which press the gravel and then lead to the compacting of the regolith as well as increasing the resistance. However, when the gravel was placed in P2, the horizontal motion component of the scoop would increase to a state which is larger than the perpendicular motion component. The main resistance was the friction, which was less than that 


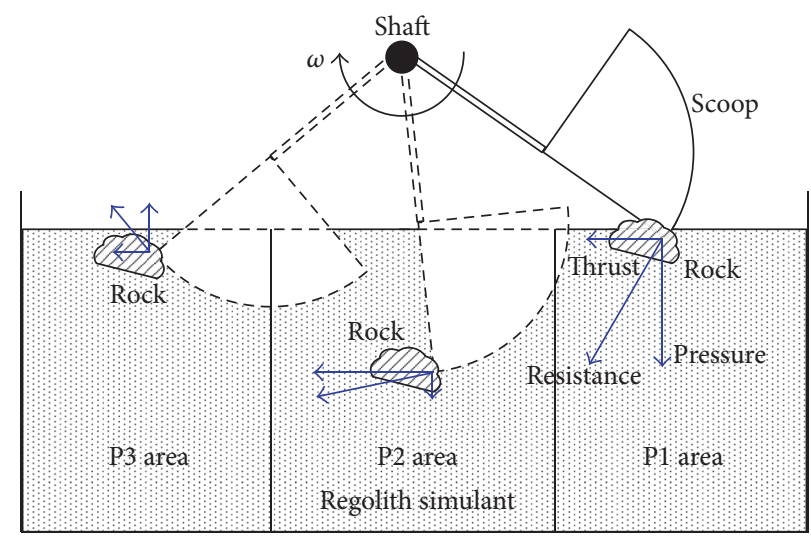

FIGURE 13: Gravel force analysis diagram.

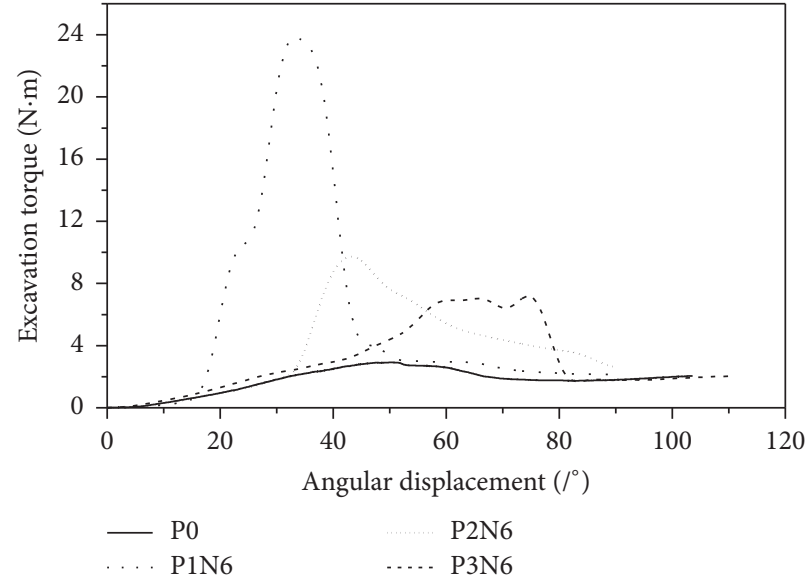

(a) Influence of the gravel position

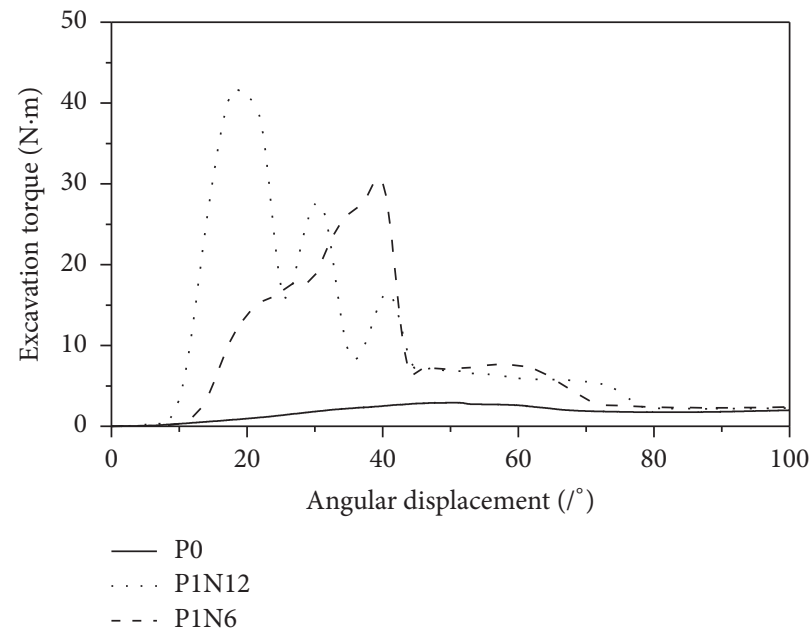

(b) Influence of the number of gravels

Figure 14: Influence of the small gravels on the excavation torque. The bulk density was loose, the penetration angle was 60 degrees, the rotating speed was $0.28 \mathrm{r} / \mathrm{min}$, P0 contained no gravels, P1N6 contained six small gravels in the P1 area, P2N6 contained six small gravels in the $\mathrm{P} 2$ area, $\mathrm{P} 3 \mathrm{~N} 6$ contained six small gravels in the P3 area, and P1N12 contained 12 small gravels in the P1 area.

of the soil press resistance. The gravel force analysis is shown in Figure 13.

The excavation torque versus the angular displacement is shown in Figure 14 for the gravels. The maximum excavation torque occurred in the $\mathrm{P} 1$ area and the minimum average torque occurred when no gravels were presented. The maximum torque of $\mathrm{P} 1, \mathrm{P} 2$, and $\mathrm{P} 3$ was $7.4,10.34$, and 23.97 N.m, respectively. The results from Figures 12 and 14 indicate that the effect of the small gravels was less than that of the large gravel because the scoop did not always interact with all six small gravels. The distribution of the gravels had an influence on the excavation torque (Figure 14(b)), and the torque increased with the number of gravels. The maximum torque of P1 N6 and P1 N12 increased by 436\% and 334.9\% over $\mathrm{P} 0$, respectively.

The impact site is important for the Lander, but the presence of gravels and a crater is unavoidable. The bulk density of the regolith in the crater is greater than that on the flat ground, and the lunar surface has gravels of various diameter, size, shape, and position. In addition, the vertical distribution of gravels from the surface to the bottom is nonuniform. The gravels under the lunar surface cannot be seen by the camera. The test results indicate that the gravels and the bulk density influence the excavation torque. However, the behaviour of the scoop, when and where it meets the gravel, is unpredictable. Thus, it is necessary to test and analyze the changes in resistance when gravels are present and for different bulk densities, and if the excavation torque sharply increases, the operation should be stopped immediately.

\section{Conclusions}

Excavation sampling has three stages, digging into, digging out, and uplift. In all three stages the regolith was sheared and compacted by the scoop. The regolith condition, rotating speed, and penetrating angle will affect the failure planes in great degree. 
The results reveal that the penetrating angle and the bulk density influenced the excavation torque greatly, due to the change in the quality of the regolith in the scoop, the cutting force, and the friction between the scoop and the regolith. Reducing the penetrating angle decreased the resistance; at the same time the efficiency also dropped. The rotating speed had little influence on the excavation torque under loose regolith conditions; however, it greatly influenced the excavation torque when the bulk density was compact.

The size, position, and number of gravels influenced the interaction between the scoop and the regolith. The excavation torque increased sharply when the scoop encountered the stones. In particular, the torque was greater at the digging into stages. When a sharp increase in excavation torque occurs, the operation should be stopped immediately.

\section{Competing Interests}

The authors declare that there is no conflict of interests.

\section{Acknowledgments}

The present work is supported by the National Natural Science Foundation of China (Grant no. 51375199), Science Fund of Shanghai Key Laboratory of Spacecraft Mechanism (Grant no. 1412005), and National Defense Researching Fund of Jilin University (Grant no. 419140100008).

\section{References}

[1] Y. Ling, W. Lu, A. Song, and H. Zeng, "In situ regolith bulk density measurement for a coiling-type sampler," Journal of Aerospace Engineering, vol. 27, no. 2, pp. 359-368, 2014.

[2] A. Green and K. Zacny, "Effect of Mars atmospheric pressure on percussive excavation forces," Journal of Terramechanics, vol. 51, no. 1, pp. 43-52, 2014.

[3] S. Frimpong and Y. Li, "Stress loading of the cable shovel boom under in-situ digging conditions," Engineering Failure Analysis, vol. 14, no. 4, pp. 702-715, 2007.

[4] R. Yousefi Moghaddam, A. Kotchon, and M. G. Lipsett, "Method and apparatus for on-line estimation of soil parameters during excavation," Journal of Terramechanics, vol. 49, no. 3-4, pp. 173-181, 2012.

[5] L. E. Bernold, "Experimental studies on mechanics of lunar excavation," Journal of Aerospace Engineering, vol. 4, no. 1, pp. 9-22, 1991.

[6] L. L. Johnson and R. H. King, "Measurement of force to excavate extraterrestrial regolith with a small bucket-wheel device," Journal of Terramechanics, vol. 47, no. 2, pp. 87-95, 2010.

[7] R. H. King, P. Van Susante, and M. A. Gefreh, "Analytical models and laboratory measurements of the soil-tool interaction force to push a narrow tool through JSC-1A lunar simulant and Ottawa sand at different cutting depths," Journal of Terramechanics, vol. 48, no. 1, pp. 85-95, 2011.

[8] M. Bucek, J. H. Agui, X. Zeng, and R. A. Wilkinson, "Experimental measurements of excavation forces in lunar soil test beds," in Proceedings of the 11th Aerospace Division International Conference on Engineering, Science, Construction, and Operations in Challenging Environments, pp. 1-10, Long Beach, Calif, USA, March 2008.
[9] J. H. Agui, M. Bucek, A. Degennaro, R. A. Wilkinson, and X. Zeng, "Lunar excavation experiments in simulant soil test beds: Revisiting the surveyor geotechnical data," Journal of Aerospace Engineering, vol. 26, no. 1, pp. 117-133, 2013.

[10] H. H. Bui, T. Kobayashi, R. Fukagawa, and J. C. Wells, "Numerical and experimental studies of gravity effect on the mechanism of lunar excavations," Journal of Terramechanics, vol. 46, no. 3, pp. 115-124, 2009.

[11] W. W. Boles, W. D. Scott, and J. F. Connolly, "Excavation forces in reduced gravity environment," Journal of Aerospace Engineering, vol. 10, no. 2, pp. 99-103, 1997.

[12] B. M. Willman and W. W. Boles, "Soil-tool interaction theories as they apply to lunar soil simulant," Journal of Aerospace Engineering, vol. 8, no. 2, pp. 88-99, 1995.

[13] J. Q. Li, M. Zou, Y. Jia, C. Chen, and W. Z. Ma, "Lunar soil simulant for vehicle-terramechanics research in laboratory," Journal of Rock and Soil Mechanics, vol. 29, no. 6, pp. 1557-1561, 2008.

[14] R. Score, C. Dardano, and G. Heiken, Handbook of Lunar Soils, Lyndon B. Johnson Space Center, 1983.

[15] J. K. Mitchell, W. N. Houston, R. F. Scott et al., "Mechanical properties of lunar soil: density, porosity, cohesion, and angle of internal friction," in Proceedings of the Lunar and Planetary Science Conference Proceedings, vol. 3, p. 3235, 1972. 


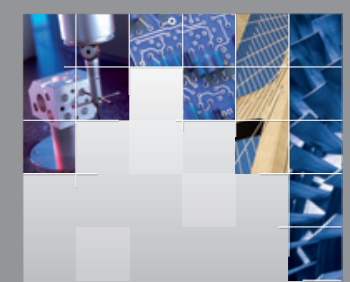

\section{Enfincering}
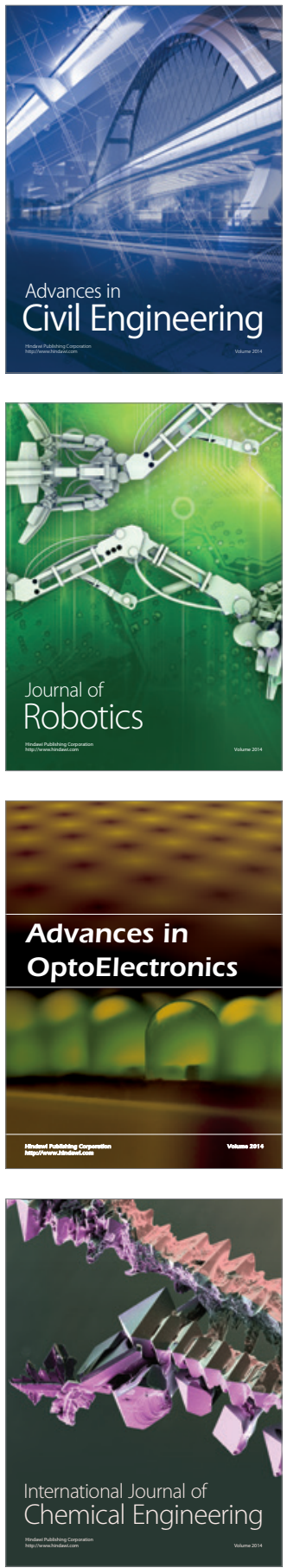

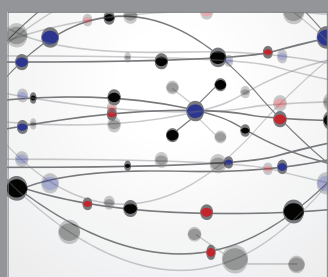

The Scientific World Journal

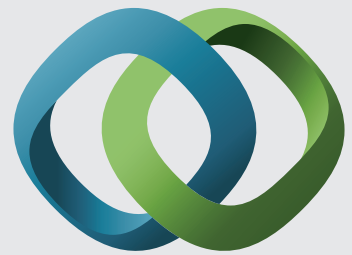

\section{Hindawi}

Submit your manuscripts at

http://www.hindawi.com
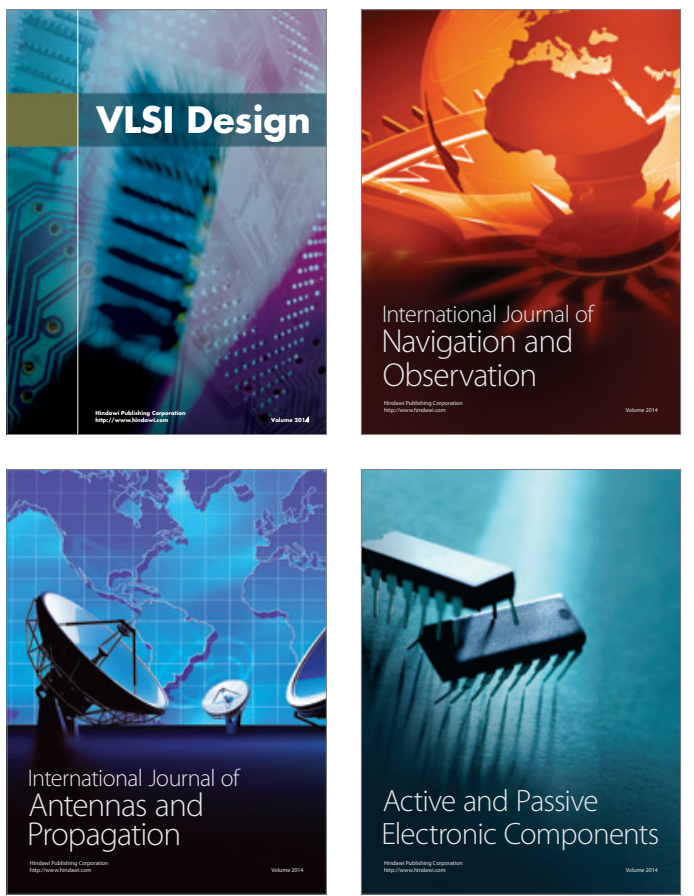
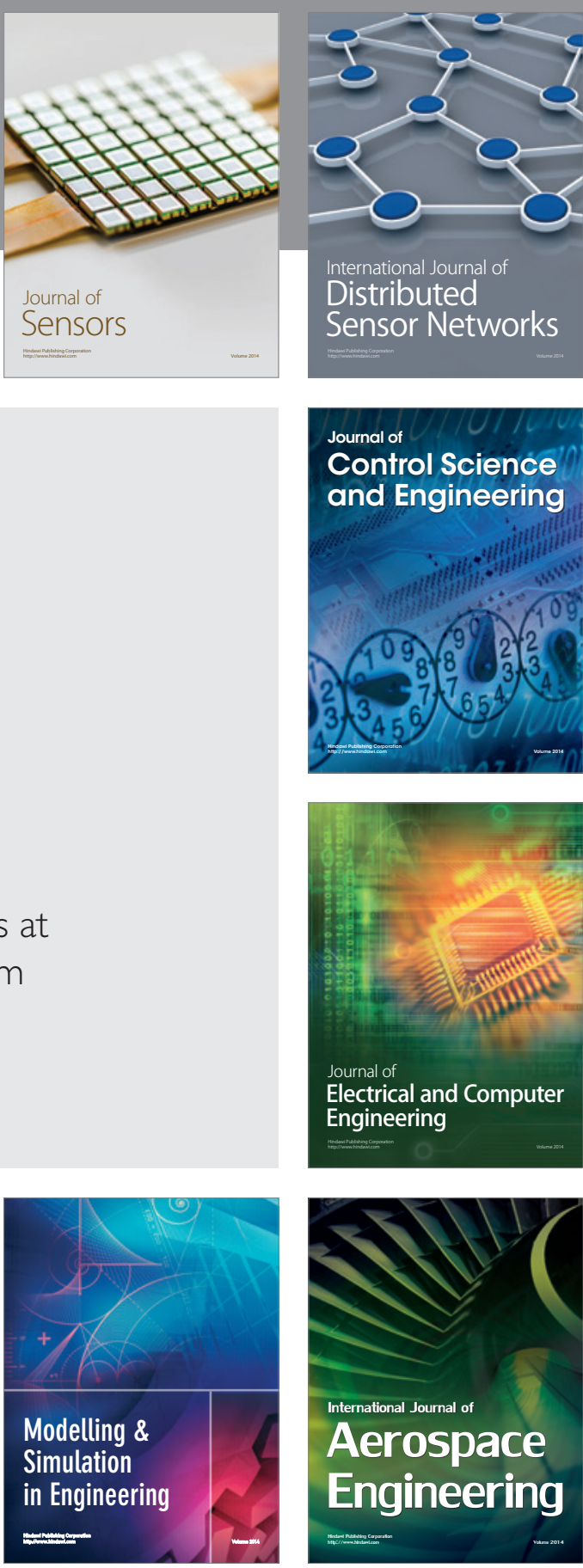

International Journal of

Distributed

Sensor Networks

Journal of

Control Science

and Engineering
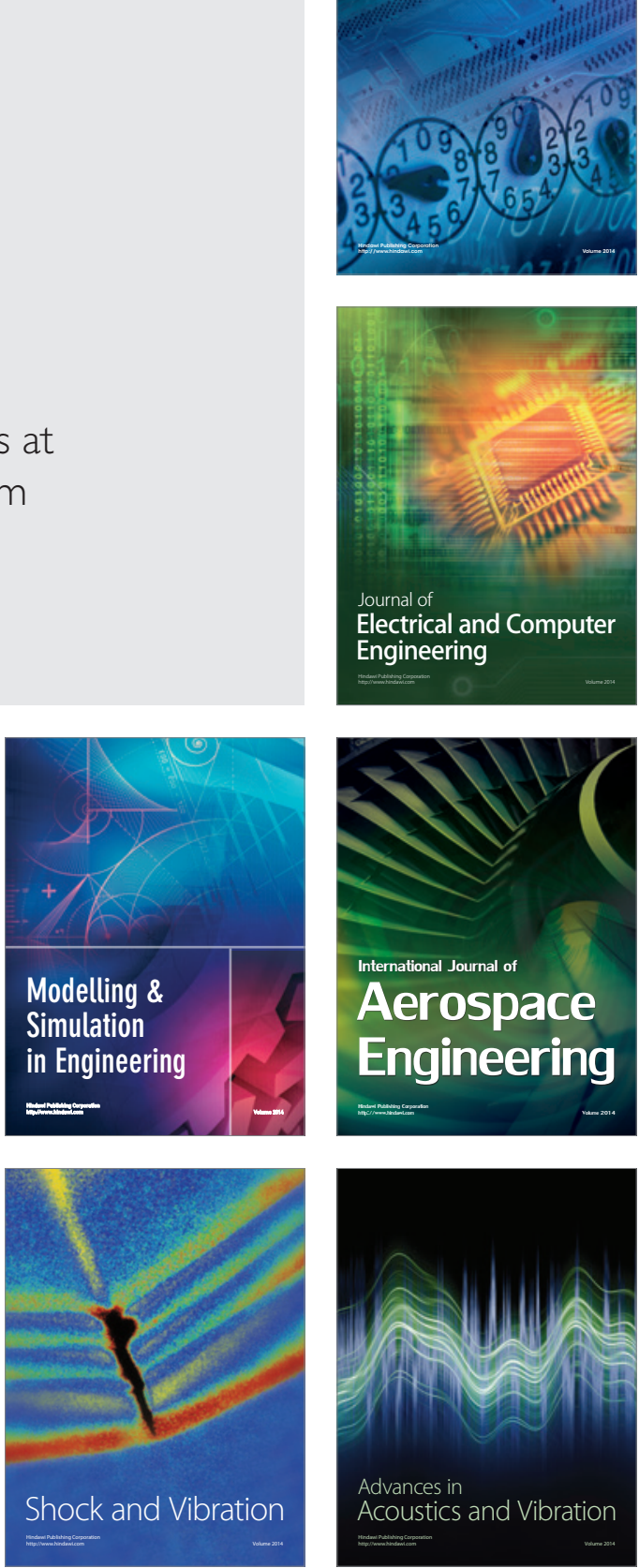